\title{
School closures during the coronavirus disease 2019 outbreak
}

\author{
Eun Young Cho, $M D^{1}$, Young June Choe, $\mathrm{MD}^{2}$ \\ ${ }^{1}$ Department of Pediatrics, Chungnam National University Hospital, Daejeon, Korea; ${ }^{2}$ Department of Pediatrics, Korea University Anam Hospital, Seoul, Korea
}

School closures during the coronavirus disease 2019 (COVID19) pandemic have been outlined in studies from different disciplines, including economics, sociology, mathematical modeling, epidemiology, and public health. In this review, we discuss the implications of school closures in the context of the current COVID-19 pandemic. Modeling studies of the effects of school closures, largely derived from the pandemic influenza model, on severe acute respiratory syndrome coronavirus 2 produced conflicting results. Earlier studies assessed the risk of school reopening by modeling transmission across schools and communities; however, it remains unclear whether the risk is due to increased transmission in adults or children. The empirical findings of the impact of school closures on COVID-19 outbreaks suggest no clear effect, likely because of heterogeneity in community infection pressure, differences in school closure strategies, or the use of multiple interventions. The benefits of school closings are unclear and not readily quantifiable; however, they must be weighed against the potential high social costs, which can also negatively affect the health of this generation.

Key words: Coronavirus, School, Child

\section{Key message}

- Earlier modeling studies of the effects of school closures on severe acute respiratory syndrome coronavirus 2 were largely derived from the pandemic influenza model, resulting in conflicting implications.

- Observational findings suggest no clear effect of school closures on community transmission or overall mortality.

- School closures must be weighed against potential high social costs, which can also negatively affect children's health.

\section{Introduction}

As of March 14, 2021, the World Health Organization officially reported $119,220,681$ confirmed cases of coronavirus disease 2019 (COVID-19), including 2,642,826 deaths. ${ }^{1)}$ The current data suggest that children under the age of 18 years represent less than $10 \%$ of reported cases, with relatively few deaths compared to elderly people. ${ }^{2)}$ The third wave of the pandemic at the end of 2020 has shifted the age proportion to younger individuals; however, students accounted for less than $15 \%$ of patients during all periods. Moreover, increasing empirical evidence suggests that schools are not the driving force of community outbreaks in many parts of the world. ${ }^{3)}$ In this context, global public health agencies are discussing their pandemic mitigation protocols that include school-related public health measures. ${ }^{4)}$

School closures are among the nonpharmaceutical interventions suggested for controlling pandemic influenza. ${ }^{5)}$ The rationales for school closures are that children may act as an important vector of transmission, and with high contact rates in schools, children may drive community outbreaks of influenza. ${ }^{6}$ School closures may be beneficial depending on characteristics including age-specific attack rates. ${ }^{7}$ However, in the current COVID-19 context, this logic does not apply since more than $90 \%$ of individuals infected with severe acute respiratory syndrome coronavirus-2 (SARS-CoV-2) are adults and many case clusters have occurred outside of schools. An early summary of data on school closures found that none of the included studies were designed to specifically examine their effectiveness and were of relatively low quality. $\left.{ }^{8}\right)$ Therefore, it is worth discussing whether school closures during the COVID-19 community outbreak effectively break the chains of transmission despite the following potential harms: diminished educational rights of children; and inaccessibility to essential health care, which affects chronic diseases and mental health that instead contribute to reduced community-wide resilience.

School closures during the COVID-19 pandemic have been discussed in studies from different disciplines, including economics, sociology, mathematical modeling, epidemiology, and public health. In this review, we discuss the impact of school closures on the current COVID-19 pandemic. 


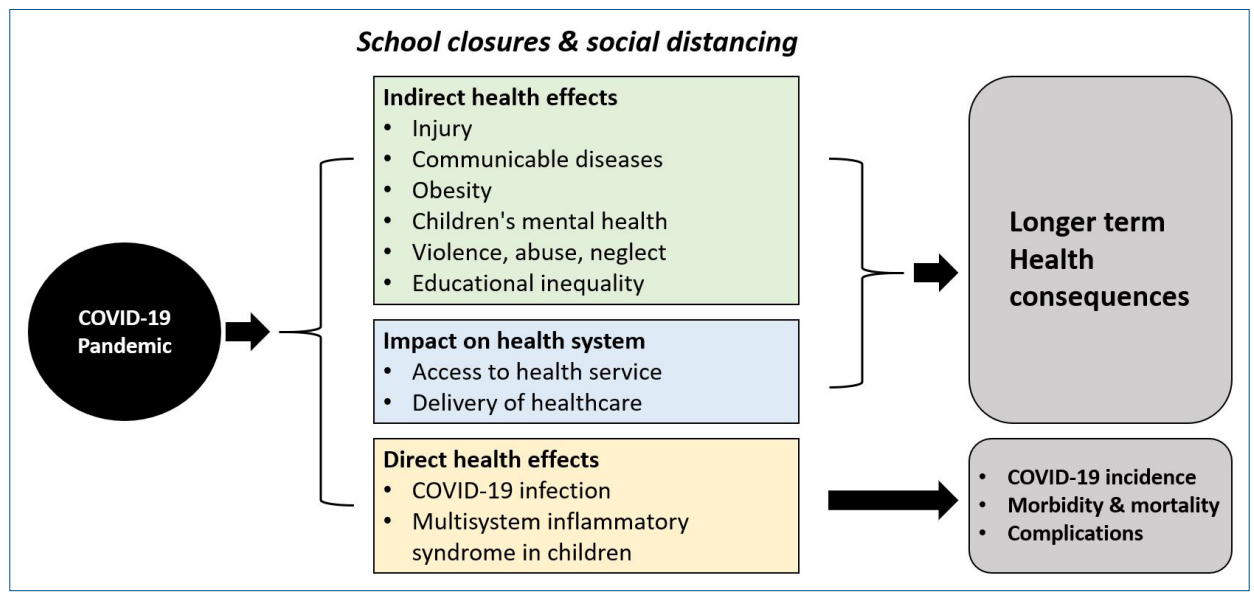

Graphic abstract

Table 1. Mathematical models simulating the effects of school closures on coronavirus disease-associated health outcomes

\begin{tabular}{|c|c|c|c|}
\hline Setting & Model & Implication & Reference \\
\hline UK, US & Individual-based simulation model & $\begin{array}{l}\text { Suppression will minimally require a combination of social distancing of the entire } \\
\text { population, home isolation of cases and household quarantine of their family members, } \\
\text { which may need to be supplemented by school and university closures, though it } \\
\text { should be recognized that such closures may have negative impacts on health systems } \\
\text { due to increased absenteeism. }\end{array}$ & 9 \\
\hline Korea & $\begin{array}{l}\text { Susceptible-exposed-Infectious- } \\
\text { Recovered model }\end{array}$ & $\begin{array}{l}\text { The increase in the number of children after school starts is likely to lead to the spread } \\
\text { of the virus to parents, grandparents, and other adults around the children. An increase } \\
\text { in incidence in the elderly age group is at risk of leading to an increase in mortality. }\end{array}$ & 10 \\
\hline UK & Individual-based model (IBMIC) & $\begin{array}{l}\text { Adding school and university closures to case isolation, household quarantine, and social } \\
\text { distancing of over } 70 \text { s would lead to more deaths compared with the equivalent } \\
\text { scenario without the closures of schools and universities. }\end{array}$ & 11 \\
\hline Canada & $\begin{array}{l}\text { Susceptible-exposed-asymptomatic- } \\
\text { infectious-recovered-hospitalized- } \\
\text { isolated model }\end{array}$ & $\begin{array}{l}\text { Though a slight increase in infections among adults }(2.8 \%) \text { and children }(5.4 \%) \text { is } \\
\text { anticipated by the end of the year, safe school opening is possible with stringent } \\
\text { nonpharmaceutical interventions decreasing the risk of transmission in the community } \\
\text { and the household. }\end{array}$ & 12 \\
\hline
\end{tabular}

UK, United Kingdom; US, United States.

\section{Mathematical modeling of health outcomes}

Modeling studies of school closures due to SARS-CoV-2 have produced conflicting results (Table 1). One of the earliest models predicted that school and university closures would reduce the transmission of COVID-19 under the assumption that children transmit SARS-CoV-2 as much as adults. ${ }^{9}{ }^{9}$ However, the study reported that school closures may be insufficient to mitigate the epidemic in isolation in contrast to seasonal influenza, of which children are the key drivers of transmission. Similarly, assuming that the transmission rate among children would increase 10fold after schools reopened, a Korean simulation study showed that school closures would be an essential nonpharmacological intervention to mitigate the COVID-19 epidemic. ${ }^{10)}$

Although earlier studies assessed the risk of school reopening by modeling transmission across schools and communities, it remains unclear whether the risk is due to increased transmission in adults or children. A subsequent model predicted that school closures would paradoxically increase the total number of deaths, suggesting that prompt interventions prolonged the epidemic, resulting in more deaths long term. ${ }^{11)}$ One criticism of school closures is that reduced contact at school may lead to increased contact at home, meaning that children would infect high-risk adults rather than low-risk children. A Canadian study found that the resurgence of COVID-19 in Toronto in the fall of 2020 mainly resulted from the increase in contact rates among adults in the community. ${ }^{12)}$ While community spread determined outbreak trajectory and school reopening was not a key driver of viral resurgence, brief school closures still reduced infections when transmission risk within the home was low. ${ }^{13)}$ Given that COVID-19-related mortality is highly skewed toward older age groups, it is reasonable to conclude that the optimal strategy differs from that anticipated for an influenza pandemic.

\section{Empirical findings in mitigating outbreaks}

Observational findings suggest that school closures have limited effects on the spread of or mortality due to SARS-CoV-2. This may have been due to heterogeneity in community infection pressure, different school closure strategies, or the use of multiple interventions. However, the transmission of SARS-CoV-2 seemed relatively infrequent in the school setting considering the volume of the population and time spent within the space. A 
systematic review of 5 cohort studies comprising 3,345 contacts with 18 transmissions in schools resulted in an overall attack rate of $0.08 \%$ (95\% confidence interval [CI], 0.00\%-0.86\%). ${ }^{14)} \mathrm{In}$ Ireland, of 1,001 child contacts of 6 confirmed index cases, there were no secondary cases of COVID-19, suggesting that schools were not drivers of transmission. ${ }^{15)}$ In Germany, the reopening of schools in May 2020 showed that child-to-child transmission in schools/childcare facilities was very uncommon. ${ }^{16)}$ The researchers estimated that there could be one secondary case per roughly 25 infectious school days. In the setting of increasing SARS-CoV-2 community transmission in France, the spread among children and adolescents remained lower than that observed among adults despite schools remaining open. ${ }^{17)}$ Mandatory in-school COVID-19 testing was performed in a reopened all-girls private school $(\mathrm{N}=701)$ in New York, United States (US). ${ }^{18)} \mathrm{A}$ total of 2,439 tests administered from October 2020 to December 2020 resulted in 3 positive cases ( 2 students, 1 staff member) for an infection rate of $0.13 \%$.

Despite these findings, the level of community transmission may affect the risk of in-school transmission of SARS-CoV-2. During the community transmission of SARS-CoV-2 in northern Italy, after school reopening in late 2020, the overall secondary case attack rate was 3.2\%, reaching $6.6 \%$ in middle and high schools. ${ }^{19)}$ Following the reopening of schools in Israel in May 2020, a major outbreak of COVID-19 occurred in a high school, resulting in 153 students (attack rate, 13.2\%) and 25 staff members (attack rate, 16.6\%) testing positive for COVID-19. ${ }^{20}$ )

In this context, a pandemic preparedness plan is important to ensuring safe school reopening. In Norway, between August and November 2020, all in-school contacts were systematically tested twice during quarantine. ${ }^{21)}$ With preventive measures implemented in schools, minimal child-to-child (0.9\%, 2 of 234) transmission occurred, suggesting that children under 14 years of age are not drivers of SARS-CoV-2 transmission. In Australia, most schools remained open during the first COVID-19 epidemic wave when 15 schools had children or adults in attendance while infectious with 1,448 contacts monitored. ${ }^{22)}$ Of them, $633(43.7 \%)$ were tested, with 18 secondary cases identified, resulting in a low attack rate of $1.2 \%$. In Santiago, Chile, a serosurvey following a school closure demonstrated antibody positivity rates of $9.9 \%$ (95\% CI, 8.2\%-11.8\%) for 1,009 students and 16.6\% (95\% CI, 12.1\%-21.9\%) for 235 staff, suggesting that the teachers were more extensively affected during the outbreak and that younger children were at higher infection risk, likely because the index case were teachers and/or parents from the preschool. ${ }^{23)}$ Despite widespread community transmission in Hong Kong during July and August 2020, cases among school-aged children were reported but did not lead to school outbreaks, likely due to stringent infection control measures adopted by local schools during school resumption. ${ }^{24)}$

In line with the aforementioned countries, a stepwise reopening of schools in South Korea resulted in no sudden increase in pediatric cases, and the proportion of pediatric cases among all confirmed cases in the nation remained at less than 10\%. ${ }^{25)}$ After the schools reopened in South Korea in May 2020, a total of 127 pediatric COVID-19 cases were confirmed by July $\left.12,2020 .{ }^{26}\right)$ Of them, 59 children (46\%) were exposed to COVID-19 through family and relatives, followed by 18 children (14\%) through cram schools or private lessons, 8 children (6\%) through multiuse facilities, and 3 children (2\%) through school.

The results from South Korea and other countries indicate that keeping schools open had minor consequences for the overall transmission of SARS-CoV-2 in the community. The empirical results for global school closure/reopening in 2020 suggest that measures to sustain education are feasible if community transmission is under control and educational facilities have doable pandemic preparedness plans.

\section{Impact of school closures on noninfectious health outcomes}

School closures have significant noninfectious health consequences. The imminent health effects on various aspects of child health include injury, obesity, mental health, and domestic violence. The containment measures in responding to the COVID-19 pandemic have resulted in reduced patterns of healthcare utilization in pediatric emergency medicine in Italy, ${ }^{27)}$ Spain, ${ }^{28)}$ and the US. ${ }^{29)}$ In Korea, there was a striking decrease in pediatric emergency visits, especially among children in early childhood (66.5\%), those with low acuity (55.2\%-63.8\%), and those visiting for noninjury complaints $(64.9 \%) .{ }^{30)}$ Thus, the impact seemed larger in children than in adults, as during the outbreak in Daegu, Korea, the number of adult patients seeking emergency care decreased by $46.4 \%$, whereas the decrease in children was $76.9 \% .{ }^{31)}$ The school closure also affected child obesity worldwide. In the US, the overall obesity prevalence in children increased from 13.7\% (June to December 2019) to 15.4\% (June to December 2020). ${ }^{32)}$ As children were confined to their homes during lockdown in France, a profound decrease in their physical activity was noted. ${ }^{33)}$ A study from Korea suggested that child obesity during the COVID-19 pandemic was associated with the number of days after school closure $(P=0.004) .{ }^{34)}$ From the early stage of the COVID-19 pandemic in 2020, research was urgently needed of children's mental health in relation to the adoption of school closures as a pandemic mitigation strategy. ${ }^{35)}$ School closures resulted in students spending more time with family; however, their sleep rhythms, eating habits, and physical activities were easily disrupted. ${ }^{36}$ A recent systematic review showed that children and adolescents were more likely to experience high rates of depression and anxiety during and after a pandemic. ${ }^{37)}$ To address students' noninfectious disease-related health issues and strengthen their coping resources, the entire community should provide students with resources to improve their well-being. 


\begin{tabular}{|c|c|}
\hline Situation & Instructions \\
\hline Before coming to schools & $\begin{array}{l}\text { Online education prior to school attendance about personal hygiene and virus prevention measures } \\
\text { Self-health check list } \\
\text { Diagnostic testing when having symptoms }\end{array}$ \\
\hline In schools & $\begin{array}{l}\text { Wear face masks and check their body temperature } \\
\text { Ventilate classrooms, stagger break times, disinfect public surfaces and objects, provide safe meals }\end{array}$ \\
\hline $\begin{array}{l}\text { When a COVID-19 case is confirmed } \\
\text { among school members }\end{array}$ & $\begin{array}{l}\text { Quarantine the school members (students, teachers, and staff members) and transit all classes into online } \\
\text { learning } \\
\text { Initiate investigation to identify suspected cases in cooperation with health authorities }\end{array}$ \\
\hline
\end{tabular}

COVID-19, coronavirus disease 2019.

\section{School COVID-19 preparedness plans in Korea}

The Korean Ministry of Education announced its guidelines on COVID-19 control and prevention (Table 2) ${ }^{38)}$ and stated that schools could reopen once able to implement "distancing in daily life." The number of students attending classes was limited to avoid overcrowding in schools.

Students received online education prior to school reopening about personal hygiene, viral transmission prevention measures, and procedures to follow in case of suspected symptoms. COVID-19-related symptoms were listed on a self-health checklist (i.e., fever, cough, sore throat, shortness of breath, and loss of smell and taste) that was to be thoroughly examined at home before children went to school. If students showed symptoms of COVID-19, they were guided to visit health clinics or screening centers for diagnostic testing.

All students and teachers were required to wear face masks and check their body temperatures twice daily. In addition, ventilating classrooms, staggering break times, and disinfecting public surfaces and objects such as desks and doorknobs were highly encouraged. To provide school meals safely, provisions were taken to limit the extent to which students mixed with each other, and all school cooks and cafeteria staff checked their health twice daily.

With these guidelines still in place, if a case of COVID-19 is confirmed among school members, students, teachers, and staff members are requested to self-quarantine. The school is requested to temporarily transition all classes to online learning and initiate investigations to identify suspected cases.

\section{Future considerations in decision-making of school openings in Korea}

In Korea, school openings, including the number of students attending classes and switching online and offline classes, differ according to the levels of social distancing. ${ }^{25)}$ In March 2021, reports of COVID-19 outbreaks in children and adolescents increased in Korea. However, these mainly occurred through daycare centers and private classes, where preventive measures for transmission of SARS-CoV-2 were not strictly applied. There have been no reports of outbreaks in elementary schools, and preventive measures in schools are working well. ${ }^{39)}$ Therefore, a nationwide plan to maintain or expand in-person school openings despite COVID-19 community outbreaks is needed, as is thorough compliance with prevention policies in schools.

Some strategies to maintain school opening include the rapid detection of SARS-CoV-2 in school members. Within educational settings, rapid antigen detection tests can be applied for contact tracing and screening of staff or students in highprevalence settings as part of a school-wide testing approach. Rapid antigen tests offer multiple benefits of speed, capacity, near-patient use (point-of-care), and low cost. However, rapid antigen tests have lower sensitivity and specificity than reverse transcription-polymerase chain reaction, so the validated performance criteria of rapid antigen tests and consideration of the overall prevalence of SARS-CoV-2 in the population should be considered. Trained personnel are needed to perform sampling, testing, and analyses and report the test results. ${ }^{40)}$

There are issues with new variants of SARS-CoV-2 with increased transmissibility. New variants have emerged globally, and some are spreading rapidly. Early data on a new variant called B.1.1.7, first detected in the United Kingdom in November 2020, found that its proportions were higher in children than in people of other ages, suggesting that it was spreading more easily in children than in adults. ${ }^{41)}$ To date, the variant seems to spread more efficiently than other lineages in all age groups. However, if another new variant increases infection rates, especially in children, then the dynamics of transmission in schools should be reinvestigated. Nonetheless, school closures could have devastating social impacts in children, including lost education and potential adverse effects on health problems. ${ }^{42)}$

\section{Conclusion}

Although schools were closed globally during 2020, substantial debate persists on whether school closure policies should be continued amid the COVID-19 pandemic. $^{42)}$ The recent consensus suggests a limited scale of benefits from school closures, and recent reviews highlighted the unexpected harm to child health. The benefits of closing are unclear and not readily quantifiable; however, they must be weighed against the potential high social costs, which can also negatively affect the health of this future generation. 


\section{ORCID}

Eun Young Cho (D https://orcid.org/0000-0002-2286-4593

Young June Choe (D https://orcid.org/0000-0003-2733-0715

\section{Conflicts of interest}

No potential conflict of interest relevant to this article was reported.

\section{References}

1. World Health Organization. Coronavirus (COVID-19) dashboard [Internet]. Geneva (Switzerland): World Health Organization; 2021 [cited 2021 Mar 21]. Available from: https://covid19.who.int/.

2. World Health Organization. Coronavirus disease (COVID-19): schools [Internet]. Geneva (Switzerland): World Health Organization; 2021 [cited $2021 \mathrm{Mar} 21$ ]. Available from: https://www.who.int/news-room/ q-a-detail/coronavirus-disease-covid-19-schools\#: :text $=$ So $\% 20$ far\%2C\%20data\%20suggests,in\%20this\%20age\%20group.

3. Betz CL. COVID-19 and school return: the need and necessity. J Pediatr Nurs 2020;54:A7-9.

4. World Health Organization. Considerations for school-related public health measures in the context of COVID-19 [Internet]. Geneva (Switzerland): World Health Organization; 2021 [cited 2021 Mar 21]. Available from:https:/www.who.int/publications/i/item/considerationsfor-school-related-public-health-measures-in-the-context-of-covid-19.

5. Monto AS. The risk of seasonal and pandemic influenza: prospects for control. Clin Infect Dis 2009;48 Suppl 1:S20-5.

6. Litvinova M, Liu QH, Kulikov ES, Ajelli M. Reactive school closure weakens the network of social interactions and reduces the spread of influenza. Proc Natl Acad Sci US A 2019;116:13174-81.

7. Cauchemez S, Ferguson NM, Wachtel C, Tegnell A, Saour G, Duncan B, et al. Closure of schools during an influenza pandemic. Lancet Infect Dis 2009;9:473-81.

8. Viner RM, Russell SJ, Croker H, Packer J, Ward J, Stansfield C, et al. School closure and management practices during coronavirus outbreaks including COVID-19: a rapid systematic review. Lancet Child Adolesc Health 2020;4:397-404.

9. Ferguson NM. Report 9: impact of non-pharmaceutical interventions (NPIs) to reduce COVID-19 mortality and healthcare demand [Internet]. London: Imperial College London; 2020 [cited 2021 Mar 21]. Available from: https://www.imperial.ac.uk/mrc-global-infectious-disease-analysis/ covid-19/report-9-impact-of-npis-on-covid-19/.

10. Kim S, Kim YJ, Peck KR, Jung E. School Opening Delay Effect on Transmission Dynamics of Coronavirus Disease 2019 in Korea: Based on Mathematical Modeling and Simulation Study. J Korean Med Sci 2020; 35:e143.

11. Rice K, Wynne B, Martin V, Ackland GJ. Effect of school closures on mortality from coronavirus disease 2019: old and new predictions. BMJ 2020;371:m3588.

12. Moghadas SM, Fitzpatrick MC, Sah P, Pandey A, Shoukat A, Singer BH, et al. The implications of silent transmission for the control of COVID-19 outbreaks. Proc Natl Acad Sci US A 2020;117:17513-5.

13. Yuan P, Aruffo E, Ogden N, Tan Y, Gatov E, Gournis E, et al. School and community reopening during the COVID-19 pandemic: a mathematical modeling study. medRxiv 2021.01.13.21249753. https://doi.org/10.110 1/2021.01.13.21249753

14. Xu W, Li X, Dozier M, He Y, Kirolos A, Lang Z, et al. What is the evidence for transmission of COVID-19 by children in schools? A living systematic review. J Glob Health 2020;10:021104.

15. Heavey L, Casey G, Kelly C, Kelly D, McDarby G. No evidence of secondary transmission of COVID-19 from children attending school in Ireland, 2020. Euro Surveill 2020;25:2000903.

16. Ehrhardt J, Ekinci A, Krehl H, Meincke M, Finci I, Klein J, et al.
Transmission of SARS-CoV-2 in children aged 0 to 19 years in childcare facilities and schools after their reopening in May 2020, BadenWürttemberg, Germany. Euro Surveill 2020;25:2001587.

17. Gras-Le Guen C, Cohen R, Rozenberg J, Launay E, Levy-Bruhl D, Delacourt C. Reopening schools in the context of increasing COVID-19 community transmission: the French experience. Arch Pediatr 2021;28: 178-85.

18. Smith-Norowitz TA, Hammerschlag MR, Kohlhoff S. Coronavirus disease 2019 (COVID-19) infection rates in a private school in Brooklyn, New York. Acta Paediatr 2021;110:1569-70.

19. Larosa E, Djuric O, Cassinadri M, Cilloni S, Bisaccia E, Vicentini M, et al. Secondary transmission of COVID-19 in preschool and school settings in northern Italy after their reopening in September 2020: a populationbased study. Euro Surveill 2020;25:2001911.

20. Stein-Zamir C, Abramson N, Shoob H, Libal E, Bitan M, Cardash T, et al. A large COVID-19 outbreak in a high school 10 days after schools' reopening, Israel, May 2020. Euro Surveill 2020;25:2001352.

21. Brandal LT, Ofitserova TS, Meijerink H, Rykkvin R, Lund HM, Hungnes $\mathrm{O}$, et al. Minimal transmission of SARS-CoV-2 from paediatric COVID-19 cases in primary schools, Norway, August to November 2020. Euro Surveill 2021;26:2002011.

22. Macartney K, Quinn HE, Pillsbury AJ, Koirala A, Deng L, Winkler N, et al. Transmission of SARS-CoV-2 in Australian educational settings: a prospective cohort study. Lancet Child Adolesc Health 2020;4:807-16.

23. Torres JP, Piñera C, De La Maza V, Lagomarcino AJ, Simian D, Torres B, et al. SARS-CoV-2 antibody prevalence in blood in a large school community subject to a Covid-19 outbreak: a cross-sectional study. Clin Infect Dis 2020 Jul 10;ciaa955. https://doi.org/10.1093/cid/ciaa955. Epub.

24. Fong MW, Cowling BJ, Leung GM, Wu P. Letter to the editor: COVID-19 cases among school-aged children and school-based measures in Hong Kong, July 2020. Euro Surveill 2020;25:2001671.

25. Yoon Y, Kim KR, Park H, Kim S, Kim YJ. Stepwise school opening and an impact on the epidemiology of COVID-19 in the children. J Korean Med Sci 2020;35:e414.

26. Kim EY, Ryu B, Kim EK, Park YJ, Choe YJ, Park HK, et al. Children with COVID-19 after reopening of schools, South Korea. Pediatr Infect Vaccine 2020;27:180-3.

27. Raucci U, Musolino AM, Di Lallo D, Piga S, Barbieri MA, Pisani M, et al. Impact of the COVID-19 pandemic on the Emergency Department of a tertiary children's hospital. Ital J Pediatr 2021;47:21.

28. González García LG, Rodríguez Manchón S, Mata Zubillaga D, García Aparicio C, Laso Alonso AE, Corral Hospital S, et al. Impact on admittance of children on Emergency Department of a regional hospital from north of Spain during the COVID-19 State of Alarm. Pediatr Emerg Care 2021;37:e64-5.

29. Bram JT, Johnson MA, Magee LC, Mehta NN, Fazal FZ, Baldwin $\mathrm{KD}$, et al. Where Have All the Fractures Gone? The epidemiology of pediatric fractures during the COVID-19 pandemic. J Pediatr Orthop 2020;40:373-9.

30. Choi DH, Jung JY, Suh D, Choi JY, Lee SU, Choi YJ, et al. Impact of the COVID-19 Outbreak on trends in emergency department utilization in children: a multicenter retrospective observational study in Seoul metropolitan area, Korea. J Korean Med Sci 2021;36:e44.

31. Jang KM, Ahn JY, Choi HJ, Lee S, Kim D, Lee DW, et al. Pediatric Emergency Department utilization and coronavirus disease in Daegu, Korea. J Korean Med Sci 2021;36:e11.

32. Jenssen BP, Kelly MK, Powell M, Bouchelle Z, Mayne SL, Fiks AG. COVID-19 and changes in child obesity. Pediatrics 2021;147: e2021050123.

33. Chambonniere C, Lambert C, Fearnbach N, Tardieu M, Fillon A, Genin P, et al. Effect of the COVID-19 lockdown on physical activity and sedentary behaviors in French children and adolescents: new results from the ONAPS national survey. Eur J Integr Med 2021;43:101308.

34. Kang HM, Jeong DC, Suh BK, Ahn MB. The impact of the coronavirus disease-2019 pandemic on childhood obesity and vitamin D status. J Korean Med Sci 2021;36:e21. 
35. Bahn GH. Coronavirus disease 2019, school closures, and children's mental health. Soa Chongsonyon Chongsin Uihak 2020;31:74-9.

36. Saito M, Kikuchi Y, Lefor AK, Hoshina M. Mental health in Japanese children during school closures due to the COVID-19. Pediatr Int 2021 Mar 31. Pediatr Int 2021 Mar 31. https://doi.org/10.1111/ped.14718. Epub.

37. Meherali S, Punjani N, Louie-Poon S, Abdul Rahim K, Das JK, Salam RA, et al. Mental health of children and adolescents amidst COVID-19 and past pandemics: a rapid systematic review. Int J Environ Res Public Health 2021;18:3432.

38. Ministry of Education. MOE's makes an announcement on nationwide school reopening [Internet]. Sejong (Korea): Ministry of Education; 2020 [cited 2021 Mar 21]. Available from: http://english.moe.go.kr/boardCnts/ view.do?boardID $=265 \&$ boardSeq $=80595 \& \mathrm{lev}=0 \&$ searchType $=$ null \&status $Y N=$ C\&page $=2 \& s=$ english $\& m=0301 \&$ opType $=N$.

39. Korea Disease Control and Prevention Agency. Updates on COVID-19 in Republic of Korea (as of 23 March) [Internet]. Cheongju (Korea): Korea Disease Control and Prevention Agency; 2021 [cited 2021 Mar 21].
Available from: http://ncov.mohw.go.kr/tcmBoardView.do?brdId=3\&b rdGubun $=31 \&$ dataGubun $=\&$ ncvContSeq $=5013 \&$ contSeq $=5013 \&$ board_id=312\&gubun=ALL.

40. Lewis D. What new COVID variants mean for schools is not yet clear. Nature 2021;589:503.

41. European Centre for Disease Prevention and Control. COVID-19 in children and the role of school settings in transmission - first update. Solna (Sweden); European Centre for Disease Prevention and Control, 2020.

42. UNESCO. School closures caused by coronavirus (Covid-19) [nternet]. Paris: UNESCO; 2021 [cited 2021 Mar 21]. Available from: https:// en.unesco.org/covid19/educationresponse. Published 2021. UNESCO.

How to cite this article: Cho EY, Choe YJ. School closures during the coronavirus disease 2019 outbreak. Clin Exp Pediatr 2021;64:322-7. https://doi.org/10.3345/cep.2021.00353 